\title{
Oral calcitonin
}

This article was published in the following Dove Press journal:

International Journal of Women's Health

5 September 2012

Number of times this article has been viewed

\section{Ronald C Hamdy ${ }^{1,2}$ Dane N Daley'}

'Osteoporosis Center, College of Medicine, East Tennessee State University, ${ }^{2}$ Veterans Affairs Medical Center, Johnson City, TN, USA
Correspondence: Ronald C Hamdy Professor of Medicine; Professor/Quillen Chair, Geriatric Medicine, East Tennessee State University, PO Box 70429, Johnson City, TN 376I4, USA

$\mathrm{Tel}+\mathrm{I} 4234398830$

Fax +I 4239793438

Email hamdy@etsu.edu
Abstract: Calcitonin is a hormone secreted by the $\mathrm{C}$-cells of the thyroid gland in response to elevations of the plasma calcium level. It reduces bone resorption by inhibiting mature active osteoclasts and increases renal calcium excretion. It is used in the management of postmenopausal osteoporosis, Paget's disease of bone, and malignancy-associated hypercalcemia. Synthetic and recombinant calcitonin preparations are available; both have similar pharmacokinetic and pharmacodynamic profiles. As calcitonin is a peptide, the traditional method of administration has been parenteral or intranasal. This hinders its clinical use: adherence with therapy is notoriously low, and withdrawal from clinical trials has been problematic. An oral formulation would be more attractive, practical, and convenient to patients. In addition to its effect on active osteoclasts and renal tubules, calcitonin has an analgesic action, possibly mediated through $\beta$-endorphins and the central modulation of pain perception. It also exerts a protective action on cartilage and may be useful in the management of osteoarthritis and possibly rheumatoid arthritis. Oral formulations of calcitonin have been developed using different techniques. The most studied involves drug-delivery carriers such as Eligen ${ }^{\circledR}$ 8-(N-2hydroxy-5-chloro-benzoyl)-amino-caprylic acid (5-CNAC) (Emisphere Technologies, Cedar Knolls, NJ). Several factors affect the bioavailability and efficacy of orally administered calcitonin, including amount of water used to take the tablet, time of day the tablet is taken, and proximity to intake of a meal. Preliminary results looked promising. Unfortunately, in two Phase III studies, oral calcitonin ( $0.8 \mathrm{mg}$ with $200 \mathrm{mg}$ 5-CNAC, once a day for postmenopausal osteoporosis and twice a day for osteoarthritis) failed to meet key end points, and in December 2011, Novartis Pharma AG announced that it would not pursue further clinical development of oral calcitonin for postmenopausal osteoporosis or osteoarthritis. A unique feature of calcitonin is that it is able to uncouple bone turnover, reducing bone resorption without affecting bone formation and therefore increasing bone mass and improving bone quality. This effect, however, may be dose-dependent, with higher doses inhibiting both resorption and formation. Because so many factors affect the pharmacokinetics and pharmacodynamics of calcitonin, especially orally administered calcitonin, much work remains to be done to explore the full pharmacologic spectrum and potential of calcitonin and determine the optimum dose and timing of administration, as well as water and food intake.

Keywords: oral calcitonin, osteoporosis, fractures, arthritis, pain

\section{Introduction}

The purpose of this manuscript is to provide a brief, up-to-date (as of April 2012) review on calcitonin with special emphasis on its clinical efficacy in the management of osteoporosis, arthritis, and pain and on the trials and tribulations of developing an oral formulation. 


\section{Methods}

We conducted several PubMed Medline literature searches using the following terms: calcitonin, oral calcitonin, pharmacology, pharmacokinetics, pharmacodynamics, bone turnover, osteoporosis, fractures, arthritis, adverse effects, pain, and antibodies. We restricted our search to publications in English and French and focused on clinically relevant publications. We adopted several search categories, including reviews, clinical trials, and meta-analyses. The first search was conducted in October 2011 and the last in April 2012, in order to ensure all recently published data were reviewed. We then classified the retrieved manuscripts into the various categories listed below.

\section{Calcitonin physiology}

Calcitonin is a 32-amino acid hormone secreted by the parafollicular (C-cells) of the thyroid gland to regulate calcium homeostasis. The main stimulus to calcitonin secretion is a rise in plasma ionized calcium level. ${ }^{1}$ Calcitonin inhibits bone resorption and increases renal calcium loss, thus preventing the plasma calcium level from rising. Excess calcitonin production (as seen in patients with medullary carcinoma of the thyroid) and calcitonin deficiency (as seen in patients with thyroid dysgenesis) affect neither the serum calcium level nor the bone mass, and the administration of calcitonin in therapeutic doses to normal adults does not induce hypocalcemia. Different types of calcitonin have been identified, including human, salmon, eel, and porcine. Salmon calcitonin ( $\mathrm{SCT}$ ) is the most potent, ${ }^{2}$ probably because salmon moves rapidly during its migratory course from a low-calcium environment (fresh water) to a calcium-rich environment (sea water).

\section{Calcitonin and bone turnover}

Calcitonin directly binds to receptors on the surface of the osteoclasts ${ }^{3}$ and induces rapid and reversible changes in their cytoskeleton, ${ }^{4,5}$ transiently decreasing their binding to the mineralized bone surface ${ }^{6}$ and bone resorptive activity $^{7}$ (Figures 1 and 2). Calcitonin specifically targets actively resorbing osteoclasts, and its effect is therefore more pronounced in trabecular than cortical bone, as the turnover rate is higher in the former than the latter. Calcitonin reduces the depth of resorption units, but it does not affect their numbers, ${ }^{8-10}$ does not trigger osteoclast apoptosis, and does not reduce the number of osteoclasts. ${ }^{5}$ This may have important therapeutic implications, because of the coupling that exists between bone resorption and bone formation and the effect of osteoclasts on osteoblast activity. ${ }^{11}$ Calcitonin has the potential to uncouple bone formation from bone

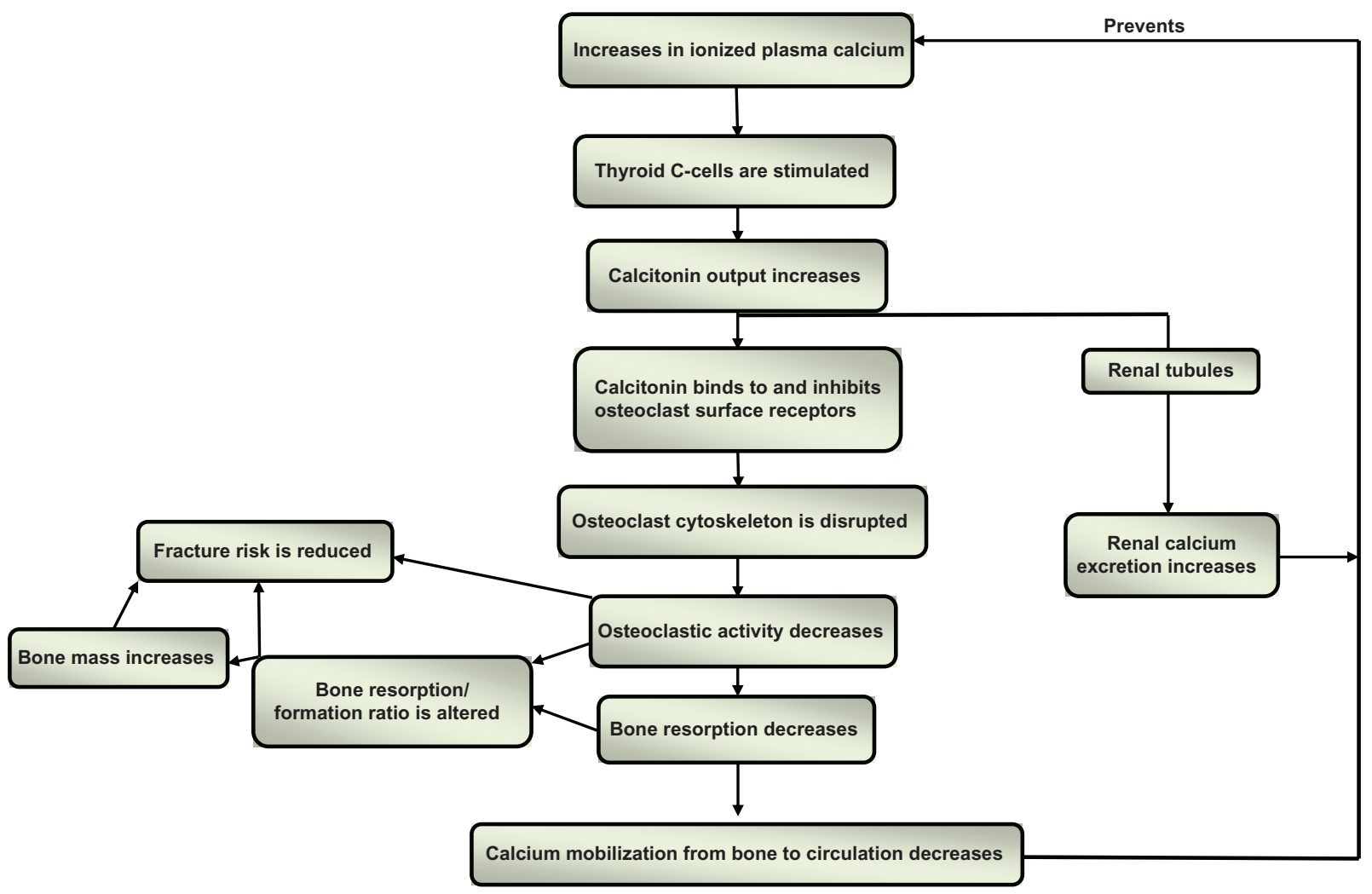

Figure I Simplified schematic representation of calcitonin, calcium homeostasis, and bone turnover. 

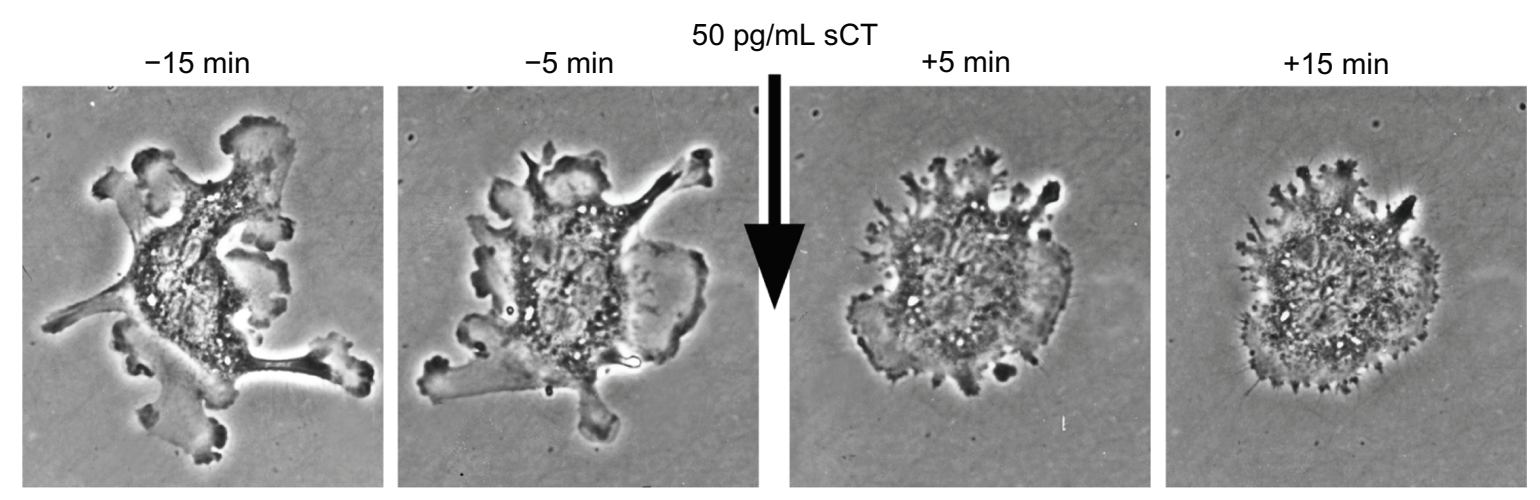

Figure 2 Rapid inhibition of osteoclast motility after treatment with salmon calcitonin (sCT) in vitro.

Notes: Time-lapse, phase-contrast images courtesy of Tim Arnett (University College London) and David Dempster (Columbia University).

resorption, reducing the latter without interfering with the former, ${ }^{12}$ provided it is administered in the appropriate dose, as an excessive dose may lead to suppression of both processes. Animal studies have indeed shown that excessive suppression of bone turnover may lead to reduced remodeling, accumulation of microcracks, and increased bone fragility. ${ }^{13,14}$

As 14 of the 32 amino acids of $\mathrm{sCT}$ are different from human calcitonin, antibodies against sCT develop in $40 \%$ to $70 \%$ of patients treated with $\mathrm{sCT}$ for more than 4 months. ${ }^{15} \mathrm{In}$ most instances, however, these antibodies are not neutralizing antibodies, they do not lead to resistance to $\mathrm{sCT}^{16}{ }^{16}$ and their clinical implications are not fully understood.

The repetitive administration of calcitonin also may diminish its inhibitory activity on osteoclasts, and its long-term administration may lead to the development of osteoclast desensitization and resistance. This is sometimes referred to as the escape phenomenon. Several mechanisms could be responsible, including internalization of calcitonin receptors (CTR) on the surface of the osteoclasts leading to reduced cell surface receptor expression, inhibition of CTR synthesis, inhibition of CTR gene expression, and reduced stability of CTR mRNA. ${ }^{17}$ The reduced inhibitory activity appears to be reversible and its clinical implications are not fully understood, as significant improvements in bone mineral density have been reported in patients administered calcitonin daily, intermittently, or cyclically; ${ }^{18-21}$ improvements in bone microarchitecture have been reported in patients who had been on intranasal $\mathrm{sCT}$ for two years $;{ }^{9}$ and daily intranasal $\mathrm{sCT}$ administration for 5 years was shown to reduce vertebral fracture risk. ${ }^{22}$

\section{Calcitonin and bone quality}

Calcitonin may improve the "quality" of osteoporotic bone, because the suppression of bone resorption it induces is only transient and not as pronounced as that induced by most other antiresorptive agents. ${ }^{5}$ This could explain the findings of the pivotal sCT clinical trial (PROOF study) on postmenopausal women with osteoporosis: At the end of the 5-year study period, $\mathrm{sCT}$ induced an increase of only about $1.5 \%$ in the bone mineral density (BMD) of the lumbar vertebrae, yet it reduced vertebral fracture risk by $33 \%$ to $36 \% .{ }^{22}$ Changes in biomarkers of bone resorption further support the positive effect of calcitonin on bone "quality": Whereas bisphosphonates induce significant decreases in the alpha/beta-C telopeptide (C-Tx) ratio (an index of bone age), calcitonin does not. ${ }^{23,24}$ Magnetic resonance imaging (MRI) assessment of trabecular microarchitecture in 91 postmenopausal women who had been administered intranasal $\mathrm{SCT}$ or placebo for 2 years showed that, compared to placebo, $\mathrm{sCT}$ induced significant improvements (or preservation - ie, no significant loss) in trabecular microarchitecture at multiple skeletal sites. ${ }^{9}$

\section{Calcitonin and fracture risk reduction}

The fracture risk reduction in patients with osteoporosis treated with calcitonin is modest and much less impressive than that induced by more potent antiresorptive agents. ${ }^{25}$ In the PROOF study, a smaller reduction in fracture risk was observed in patients administered 400 units sCT intranasally daily compared to those receiving 200 units; ${ }^{22}$ this seeming paradox may be due to the larger dose suppressing resorption to a greater extent, therefore reducing bone formation in addition to bone resorption and improving bone quality less than the smaller dose. Indeed, in the management of Paget's disease of bone, where both formation and resorption are excessive, large doses of calcitonin reduce osteoblastic as well as osteoclastic activity. Unfortunately the small number of patients enrolled in the PROOF study (1255) and the excessive withdrawal/dropout rate (59\%) make it difficult to adequately evaluate the results; only 511 subjects, allocated 
to four different treatment regimens, completed the 5-year study. The conclusion of a meta-analysis of 30 studies was that calcitonin reduces the risk of vertebral fractures and that its effect on nonvertebral fractures is uncertain. ${ }^{26}$

\section{Routes of administration of calcitonin}

As calcitonin is a polypeptide, the traditional method of administration is parenteral (subcutaneous or intramuscular) or intranasal. It also has been administered rectally. ${ }^{27}$ These routes of administration are associated with adverse effects and are inconvenient to many patients. Adherence with calcitonin therapy has been notoriously low, and the high withdrawal rates from clinical trials have been problematic. An oral preparation would be more convenient and acceptable to patients.

Several obstacles affect the bioavailability of orally administered calcitonin. Being a polypeptide, it is readily degraded by gastric acidity and digested by the proteolytic enzymes in the stomach and intestines. Orally administered calcitonin, therefore, must survive first the onslaught of the acidic medium in the stomach and then the gastric and intestinal proteases. Its size and hydrophobicity present further challenges to its intestinal absorption, as it must then cross the epithelial cells lining the intestinal mucosa without interfering with their integrity and without opening the tight junctions of the intestinal mucosa that normally inhibit the passage of large molecules. Only after successfully penetrating the intestinal mucosal cells will calcitonin enter the portal circulation and eventually reach the osteoclasts.

\section{Oral formulations of calcitonin}

Technological advances made it possible to overcome these obstacles and develop oral formulations of $\mathrm{sCT}$ using drug delivery agents or carriers, such as Eligen ${ }^{\circledR} 8$ (N-2hydroxy-5-chloro-benzoyl)-amino-caprylic acid (5-CNAC) (Emisphere Technologies, Cedar Knolls, NJ). ${ }^{28}$ These drug delivery agents contain low-molecular weight compounds that combine weakly and noncovalently with sCT to form an insoluble compound at low $\mathrm{pH}$ values, thus allowing sCT to cruise through the stomach without being degraded by the acidic medium or the gastric peptidases. ${ }^{29}$ Once it reaches the intestines, the compound dissolves in the higher $\mathrm{pH}$ environment and, being lipophilic, is absorbed via the passive transcellular pathway, passing through the epithelial cells without undergoing chemical modifications and without compromising the integrity of the intestinal mucosa. ${ }^{30}$ Once absorbed, sCT dissociates itself from the delivery agent and reestablishes itself, retaining its biologic state and potential therapeutic activity. ${ }^{5,31}$ This formulation has been tested in Phase 3 studies.

Another successful way of formulating oral calcitonin is by using an acid-resistant enteric coating that prevents dissolution in the stomach and adding citric acid to the tablet core to inhibit intestinal proteases and enhance paracellular transport across the intestinal mucosa. This formulation also has been tested in Phase III studies. ${ }^{32}$

Several other methodologies are available to develop oral formulations of calcitonin, including glycosylation with low-molecular weight polyethylene glycol oligomers to produce small amphilic oligomers resistant to proteases and absorbed through the intestinal wall; ${ }^{33}$ the addition of protease inhibitors; ${ }^{34}$ and encapsulation of $\mathrm{SCT}$ in a vehicle containing hydrophilic aromatic alcohols to protect calcitonin from proteases in the stomach and increase its permeability across the intestinal wall. ${ }^{31}$

\section{Pharmacology of oral calcitonin}

The pharmacokinetics and pharmacodynamics of orally administered calcitonin have been studied in humans. ${ }^{5}$ Following the oral administration of $0.8 \mathrm{mg} \mathrm{sCT}$ (and $200 \mathrm{mg}$ 5-CNAC), a highly linear dose response and good inverse correlation $(\mathrm{r}=-0.96)$ is demonstrated between the area under the curve for $\mathrm{sCT}\left(\mathrm{AUC}_{\mathrm{sCT}}\right)$ and for C-telopeptide $\left(\mathrm{AUC}_{\mathrm{C}-\mathrm{Tx}}\right)$, an index of bone resorption. ${ }^{35}$ Time to maximum concentration is about 15 minutes and half-life is between 9 and 15 minutes, very similar to the pharmacokinetic profile of 200 units intranasally administered sCT. Maximum concentration $\left(\mathrm{C}_{\max }\right)$, however, is much higher with oral administration than with intranasal: $145 \mathrm{pg} / \mathrm{mL}$ and $11.4 \mathrm{pg} / \mathrm{mL}$, respectively, a difference of more than tenfold. Similarly, the $\mathrm{AUC}_{\mathrm{SCT}}$ and $\mathrm{AUC}_{\mathrm{C}-\mathrm{Tx}}$ are more than tenfold higher with $0.8 \mathrm{mg}$ oral sCT than with 200 units intranasally administered $\mathrm{sCT}$, suggesting that oral $\mathrm{sCT}$ is more readily absorbed and inhibits bone resorption to a much greater extent than intranasally administered $\mathrm{sCT} \cdot{ }^{36}$ This may have significant therapeutic implications, as the greater inhibitory effect of $0.8 \mathrm{mg}$ oral sCT may negate the potential of calcitonin to uncouple bone formation from bone resorption, inhibiting both formation and resorption as opposed to just resorption. Given the differences in $\mathrm{C}_{\text {max }}, \mathrm{AUC}_{\mathrm{sCT}}$, and $\mathrm{AUC}_{\mathrm{C}-\mathrm{Tx}}$, it is possible that a dose of $0.08 \mathrm{mg}$ oral $\mathrm{sCT}$, not $0.8 \mathrm{mg}$, would have the equivalent biologic effect on bone turnover of 200 units administered intranasally. 


\section{Factors affecting pharmacokinetics of orally administered sCT}

Several factors affect the bioavailability of orally administered calcitonin, including the following:

\section{Water intake}

The amount of water used to take the sCT tablet may affect gastric emptying time and therefore may have a direct impact on $\mathrm{SCT}$ bioavailability and bone turnover. This was studied in a randomized, placebo-controlled, single-dose, exploratory crossover Phase I study on 56 healthy postmenopausal women randomly assigned to receive 5 different treatments $-0.8 \mathrm{mg} \mathrm{sCT}$ (and $200 \mathrm{mg} 5$-CNAC) with $50 \mathrm{~mL}$ or $200 \mathrm{~mL}$ of water, placebo with $50 \mathrm{~mL}$ or $200 \mathrm{~mL}$ of water, and $200 \mathrm{IU}$ sCT administered intranasally - 10, 30, and 60 minutes before a meal. ${ }^{31}$ Taking the $0.8 \mathrm{mg} \mathrm{sCT}$ tablet (and $200 \mathrm{mg} 5-\mathrm{CNAC}$ ) with $50 \mathrm{~mL}$ of water resulted in two- to threefold increases in $\mathrm{AUC}_{\mathrm{SCT}}$ compared to taking the tablet with $200 \mathrm{~mL}$ of water and a fourfold increase compared to the intranasally administered $\mathrm{sCT}$; it was also associated with a greater reduction in serum $\mathrm{C}$-Tx levels, indicating a greater reduction in the rate of bone resorption. This effect was independent of whether a meal was consumed 10,30 , or 60 minutes post-dosing, confirming the independent effect of water on the absorption of orally administered SCT. This may have important implications in clinical practice and clinical trials, as the impact on bone turnover may be quite different if a patient takes $\mathrm{sCT}$ with 50 or $200 \mathrm{~mL}$ of water; whereas a smaller reduction in bone resorption is not likely to affect bone formation, a larger suppression may also decrease bone formation.

\section{Food intake}

Food also may affect the bioavailability of orally administered sCT. Compared to dosing 10 minutes before a meal, oral dosing 1,2, and 4 hours after a meal reduces calcitonin uptake by as much as $74 \%$. This is associated with reduced efficacy as determined by changes in serum C-Tx levels. Taking the tablet 10 minutes before a meal maximizes sCT bioavailability and its effect on bone resorption. ${ }^{31}$

\section{Time of oral administration}

There are marked diurnal and postprandial variations in bone turnover. Bone resorption is about $50 \%$ higher in the fasting state than after the intake of a meal and at night during rest than during the day. ${ }^{37}$ As fasting appears to eliminate most of the circadian variation, it is possible that the observed diurnal variations are secondary to food intake and postprandial endocrine signaling. ${ }^{38,39}$ To better understand the effect of timing of oral $\mathrm{sCT}$ intake on the pharmacokinetic and pharmacodynamic profiles of orally administered $\mathrm{SCT}$, a study was conducted on 81 postmenopausal women. ${ }^{40}$ They were randomly allocated to receive either placebo or $\mathrm{SCT}(0.8 \mathrm{mg}$ recombinant $\mathrm{sCT}$ and $200 \mathrm{mg} 5$-CNAC) with $200 \mathrm{~mL}$ of water (a) at 8:00 am, after an overnight fast, followed by breakfast 1 hour after dosing (42 subjects, mean age 65.5 years); (b) at 5:00 pm, 4 hours after the previous meal and 1 hour before the next meal (20 subjects, mean age 64.6 years); or (c) at 10:00 pm 4 hours after a meal (19 subjects, mean age 64.4 years). Calcitonin was rapidly absorbed: Median time to $\mathrm{C}_{\max }$ was about 30 minutes for all dosing regimens. $\mathrm{C}_{\max }$ was $45.1,44.7$, and $23.8 \mathrm{pg} / \mathrm{mL}$ for the morning, evening, and night doses, respectively. $\mathrm{AUC}_{\mathrm{SCT}: 0-4 \text { hours }}$ was $30.6,36.3$, and 28.1, respectively. The suppression of bone turnover as determined by reductions in serum C-Tx was $40 \%$ to $50 \%$ after the morning dose and $75 \%$ after the evening and night doses. Given the diurnal and postprandial variations, maximum efficacy was observed after the evening dose, 4 hours after the previous meal and 1 hour before the next meal. ${ }^{40}$ The correlation between plasma $\mathrm{SCT}$ and $\mathrm{C}-\mathrm{Tx}$ was affected by the time of the day sCT was administered: $r=-0.96$ when administered in the evening and -0.74 when administered in the morning. ${ }^{35}$

\section{Tolerability and adverse effects}

A 3-month safety and efficacy study on 277 postmenopausal women aged 55 to 85 years showed that oral $\mathrm{SCT}$ (combined with $200 \mathrm{mg}$ delivery agent 5-CNAC) was well tolerated, the main adverse effects being mild to moderate gastrointestinal effects in the high-dose group. ${ }^{41}$ On the other hand, in a 48-week study comparing oral sCT (acid-resistant enteric coated tablets containing citric acid) to intranasal $\mathrm{sCT}$ to placebo, about a third of the subjects enrolled withdrew from the study either because of adverse effects - mostly gastrointestinal - or because of withdrawing their consent. ${ }^{32}$ As patients on placebo in this study also experienced adverse effects, it is possible that these were related to the formulation of the compound or the population included in the study. In another 24-month, Phase III, placebo-controlled clinical trial on the use of oral $\mathrm{sCT}$ twice daily $(0.8 \mathrm{mg}$ with 5 -CNAC carrier delivery system) in 1169 men and women aged 50 to 80 years with painful knee osteoarthritis, ${ }^{42}$ there were more adverse effects with oral sCT than with placebo, in particular hot flushes (17.8\% vs $4.1 \%$ ), nausea (14\% vs $3.1 \%$ ), dyspepsia (10.1\% vs $4.5 \%)$ and diarrhea (9.6\% vs $4.3 \%)$. Discontinuation because of drug-related adverse effects was 
$19.5 \%$ in the sCT group as opposed to $5.8 \%$ in the placebo group, and overall discontinuation rate was about $33 \%$ in the oral sCT group and $23 \%$ in the placebo group. In this study, however, sCT was administered twice daily. ${ }^{42}$ All oral formulations do not, therefore, have the same safety/ tolerability profile.

\section{Recombinant versus synthetic $\mathrm{sCT}$}

Both recombinant and synthetic $\mathrm{SCT}$ are available and have similar pharmacodynamic and pharmacokinetic profiles. ${ }^{31}$

\section{Efficacy of oral sCT Osteoporosis}

Several studies have documented the efficacy of oral sCT as determined by changes in biomarkers of bone resorption.

\section{Biomarkers of bone turnover, 3-month study}

A 3-month multicenter randomized, double-blind, placebocontrolled, dose-ranging study on 277 postmenopausal women aged 55 to 85 years showed that, compared to placebo, sCT (combined with $200 \mathrm{mg}$ of the delivery agent 5-CNAC) induced dose-dependent decreases in serum C-Tx reaching $81.8 \%$ of baseline value 2 to 3 hours post dosing. The formulation was well tolerated. ${ }^{41}$

\section{Bone mineral density and biomarkers of bone turnover, 48-week study (ORACAL trial)}

A Phase III multicenter, randomized, double-blind, doubledummy, placebo-controlled study included 565 postmenopausal women (46 to 86 years old) with osteoporosis, as determined by a lumbar vertebrae T-score of -2.5 or lower, or -2.0 and lower if they also had evidence of vertebral fragility fracture. Each patient was randomly allocated to one of three groups: oral recombinant $\mathrm{sCT}, 0.2 \mathrm{mg}$ taken 1 hour before sleeping; intranasal synthetic sCT, $200 \mathrm{IU}$; or placebo. All patients also received calcium and vitamin D supplements. ${ }^{32}$

Mean percentage increases in lumbar vertebrae bone mineral density in the oral, intranasal, and placebo groups at 24 weeks were $1.76 \%, 1.29 \%$, and $0.71 \%$ and at 48 weeks were $1.53 \%, 0.76 \%$, and $0.47 \%$, respectively. Changes in the levels of bone biomarkers (serum C-Tx) at 24 weeks were $-42.93 \%,-24.64 \%$, and $-21.09 \%$ and at 48 weeks were $-29.92 \%,-11.41 \%$, and $-11.83 \%$ in the oral, intranasal and placebo groups, respectively. At 48 weeks, changes in P1NP levels (a marker of bone formation) were $-24.17 \%,-12.44 \%$, and $-10.81 \%$, respectively. ${ }^{32}$ The greater decrease in P1NP levels at week 48 with the oral formulation than with the intranasal formulation $(-24.17 \%$ vs $-12.44 \%)$ may point to different degrees of inhibition of osteoclastic and osteoblastic activity when taken in association with the more pronounced reduction in C-Tx levels ( $-29.92 \%$ oral vs $-11.41 \%$ intranasal); this suggests that $0.2 \mathrm{mg}$ recombinant $\mathrm{sCT}$ may be too high a dose for treating osteoporosis, as it reduces bone formation as well as bone resorption. This observation, however, must be tempered by the large standard deviations of the measured bone biomarkers.

Results of this study are also difficult to interpret because of the relatively small number of patients included (565 randomized to three different study regimens), the short duration of the study (48 weeks), and the overall withdrawal rate $(27.3 \%, 26.5 \%$, and $19.3 \%$ in the oral, intranasal and placebo groups, respectively, because of adverse events and withdrawal of consent). Only 176, 128, and 73 participants completed the study in the respective groups. ${ }^{32}$

\section{Fracture risk, 3-year study}

A preliminary report of a multicenter, double-blind, placebocontrolled clinical trial on oral sCT $(0.8 \mathrm{mg}$ combined with $200 \mathrm{mg}$ of the delivery agent 5-CNAC) in postmenopausal women aged 55 to 85 years with osteoporosis was presented at the 2010 annual meeting of the American Society for Bone and Mineral Research in Chicago. A total of 4,665 postmenopausal women with osteoporosis were enrolled. Their mean age was $66.7( \pm 6.14)$ years; mean body mass index $26.1( \pm 4.16)$; and baseline T-score $<-2.5$ in the lumbar vertebrae, femoral neck or total hip. ${ }^{43}$ The final analysis was planned for late in 2011. On November 14, 2011, Novartis Pharma AG announced that the study failed to demonstrate a statistically significant reduction in new vertebral fractures at 3 years - the primary end point of the study - and that no significant effect was noted on secondary end points, such as nonvertebral and new clinical fractures. ${ }^{44}$ On December 14 , 2011, Novartis Pharma AG announced that it would not pursue further clinical development of oral calcitonin as a treatment option for postmenopausal osteoporosis, because oral calcitonin failed to meet key efficacy end points. ${ }^{45}$

\section{Pain}

Independent of its activity on bone turnover, calcitonin has an analgesic effect, probably due to increases in plasma $\beta$-endorphin levels ${ }^{46}$ and interaction with the endogenous opiate system. ${ }^{47}$ Calcitonin may also directly modulate pain perception through calcitonin-binding receptors in the median pontine reticular formation and the rostrocaudal 
axis of the periaqueductal gray matter. ${ }^{48}$ Calcitonin has been shown to be effective at relieving pain in patients with a number of conditions, including acute vertebral compression fractures, ${ }^{49}$ bone metastases,${ }^{50}$ Paget's disease of bone, ${ }^{51}$ postoperative pain, ${ }^{52}$ diabetic neuropathy, ${ }^{53}$ phantom limb pain, ${ }^{54}$ adhesive capsulitis, ${ }^{55}$ and reflex sympathetic dystrophy. ${ }^{56}$

\section{Osteoarthritis}

Increased cartilage degradation is an important aspect of osteoarthritis. ${ }^{57-59}$ Calcitonin receptors have been identified on the surface of articular chondrocytes, ${ }^{60}$ and calcitonin has been shown to exert a protective effect on cartilage degradation ${ }^{5,60-62}$ as measured by changes in C-terminal cross-linked telopeptide of type II collagen, which is present in cartilage. ${ }^{63,64}$

\section{Cartilage degradation, 2-week study}

A 2-week study showed that oral sCT $(0.6 \mathrm{mg}$ and $0.8 \mathrm{mg}$ with $200 \mathrm{mg} 5$-CNAC) administered twice a day led to significant reductions in the rate of cartilage degradation. ${ }^{65}$

\section{Cartilage turnover, 3-month study}

A 3-month randomized, double-blind, placebo-controlled study was conducted on 152 women aged 55 to 85 years who were randomly allocated to receive $0.15,0.4,1.0$, or $2.5 \mathrm{mg}$ oral sCT (each with $200 \mathrm{mg}$ 5-CNAC) or placebo daily. Oral calcitonin induced dose-dependent decreases in 24-hour urinary excretion rates of C-terminal cross-linked telopeptide of type I and II collagen. Greater reductions were noted in patients who had high cartilage turnover rates. ${ }^{58} \mathrm{Cal}-$ citonin therefore may have a role to play in the management of osteoarthritis, ${ }^{66-68}$ especially as it also has an analgesic effect. Calcitonin also enhances the anti-inflammatory effect of corticosteroids and reduces bone and cartilage loss, ${ }^{69}$ and therefore may have in addition a role to play in the management of rheumatoid arthritis.

\section{Osteoarthritis of the knee, 24 months}

The preliminary results of a 24-month, Phase III clinical trial on the use of oral $\mathrm{sCT}(0.8 \mathrm{mg}$ twice daily with 5-CNAC carrier delivery system) in 1169 men and women aged 50 to 80 years with painful knee osteoarthritis were presented at the 2011 American College of Rheumatology annual meeting in Chicago. ${ }^{42}$ The mean age of the enrolled subjects was 64 years; their mean body mass index was $28.9 \mathrm{~kg} / \mathrm{m}^{2}$; and $68 \%$ were women. MRI studies demonstrated a $4.5 \%$ loss of medial compartment cartilage volume in patients on oral sCT compared to a 7\% loss in those on placebo $(P=0.006)$. There were, however, no significant differences in joint-space width in the $\mathrm{SCT}$ and placebo groups. Oral sCT was statistically superior to placebo as determined by several scales: 24-hour pain score $(P=0.018)$, patient global assessment $(P=0.008)$, physician global assessment $(P=0.014)$, Western Ontario and McMaster Universities Osteoarthritis Index pain scores $(P=0.002)$, function scores $(0.013)$, and stiffness scores $(P<0.001) .{ }^{42}$ On December 14, 2011, Novartis Pharma AG announced that it will not pursue further clinical development of oral calcitonin as a treatment option for osteoarthritis because oral calcitonin failed to meet key efficacy endpoints. ${ }^{45}$

\section{Conclusion}

Calcitonin is available for the management of postmenopausal osteoporosis, Paget's disease of bone, and hypercalcemia of malignancy, but its use is limited by the need to administer it parenterally or intranasally and the associated adverse effects. Patient adherence to treatment is notoriously low, and the high withdrawal rate from clinical trials is problematic.

Calcitonin has the potential to uncouple bone resorption from bone formation, inhibiting the former without affecting the latter and thus improving bone quality. The availability of oral formulations should encourage researchers to explore the full pharmacologic spectrum and potential of calcitonin - not limited to osteoporosis, but also including pain relief and possible beneficial effects on osteoarthritis. Preliminary results look encouraging, promising and exciting, but much work remains to be done, especially to identify the optimum dose: too little is not effective, while too much may result in suppression of both bone formation and resorption and may negate the potential unique advantage of calcitonin to uncouple bone formation and resorption. As far as calcitonin is concerned, more is not better.

Given the anticipated long duration of therapy, the oral preparation must be relatively free of adverse effects, including minor gastrointestinal ones. Major challenges include determining the optimum dose and the optimum timing and frequency of oral administration. The full potential of calcitonin has yet to be appreciated.

\section{Acknowledgments}

The authors would like to thank Ms Jennifer Culp and Ms Lindy Russell for their assistance in preparing this manuscript. 


\section{Disclosure}

$\mathrm{RCH}$ is on the speakers' bureau of Novartis. His work as co-author of this manuscript has been performed outside the scope of his employment as a United States government employee. This work represents his personal and professional views and not necessarily those of the US government. DD reports no conflicts of interest in this work.

\section{References}

1. Deftos LJ, Lee MR, Potts JT Jr. A radioimmunoassay for thyrocalcitonin. Proc Natl Acad Sci U S A. 1968;60(1):293-299.

2. Hilton JM, Dowton M, Houssami S, Sexton PM. Identification of key components in the irreversibility of salmon calcitonin binding to calcitonin receptors. J Endocrinol. 2000;166(1):213-226.

3. Chambers TJ, Moore A. The sensitivity of isolated osteoclasts to morphological transformation by calcitonin. J Clin Endocrinol Metab. 1983;57(4):819-824.

4. Suzuki H, Nakamura I, Takahashi N, et al. Calcitonin-induced changes in the cytoskeleton are mediated by a signal pathway associated with protein kinase A in osteoclasts. Endocrinology. 1996;137(11): $4685-4690$

5. Henriksen K, Bay-Jensen AC, Christiansen C, Karsdal MA. Oral salmon calcitonin - pharmacology in osteoporosis. Expert Opin Biol Ther. 2010;10(11):1617-1629.

6. Shyu JF, Shih C, Tseng CY, et al. Calcitonin induces podosome disassembly and detachment of osteoclasts by modulating Pyk2 and Src activities. Bone. 2007;40(5):1329-1342.

7. Sexton PM, Findlay DM, Martin TJ. Calcitonin. Curr Med Chem. 1999;6(11):1067-1093.

8. Ikegame M, Ejiri S, Ozawa H. Calcitonin-induced change in serum calcium levels and its relationship to osteoclast morphology and number of calcitonin receptors. Bone. 2004;35(1):27-33.

9. Chesnut CH 3rd, Majumdar S, Newitt DC, et al. Effects of salmon calcitonin on trabecular microarchitecture as determined by magnetic resonance imaging: results from the QUEST study. J Bone Miner Res. 2005;20(9):1548-1561.

10. Jiang Y, Zhao J, Geusens P, et al. Femoral neck trabecular microstructure in ovariectomized ewes treated with calcitonin: MRI microscopic evaluation. J Bone Miner Res. 2005;20(1):125-130.

11. Henriksen K, Neutzsky-Wulff AV, Bonewald LF, Karsdal MA. Local communication on and within bone controls bone remodeling. Bone. 2009;44(6):1026-1033.

12. Karsdal MA, Henriksen K, Arnold M, Christiansen C. Calcitonin: a drug of the past or for the future? Physiologic inhibition of bone resorption while sustaining osteoclast numbers improves bone quality. Bio Drugs. 2008;22(3):137-144.

13. Seeman E, Delmas PD. Bone quality - the material and structural basis of bone strength and fragility. N Engl J Med. 2006;354(21): 2250-2261.

14. Martin TJ, Seeman E. New mechanisms and targets in the treatment of bone fragility. Clin Sci (Lond). 2007;112(2):77-91.

15. Grauer A, Reinel HH, Ziegler R, Raue F. Neutralizing antibodies against calcitonin. Horm Metab Res. 1993;25(9):486-488.

16. Grauer A, Ziegler R, Raue F. Clinical significance of antibodies against calcitonin. Exp Clin Endocrinol Diabetes. 1995;103(6):345-351.

17. Samura A, Wada S, Suda S, Iitaka M, Katayama S. Calcitonin receptor regulation and responsiveness to calcitonin in human osteoclast-like cells prepared in vitro using receptor activator of nuclear factor-kappaB ligand and macrophage colony-stimulating factor. Endocrinology. 2000;141(10):3774-3782.

18. Tekeoğlu I, Adak B, Budancamanak M, Demirel A, Ediz L. Comparison of cyclic and continuous calcitonin regimens in the treatment of postmenopausal osteoporosis. Rheumatol Int. 2005;26(2):157-161.
19. Kaskani E, Lyritis GP, Kosmidis C, et al. Effect of intermittent administration of $200 \mathrm{IU}$ intranasal salmon calcitonin and low doses of 1alpha $(\mathrm{OH})$ vitamin $\mathrm{D} 3$ on bone mineral density of the lumbar spine and hip region and biochemical bone markers in women with postmenopausal osteoporosis: a pilot study. Clin Rheumatol. 2005;24(3): 232-238.

20. Ushiroyama T, Ikeda A, Sakai M, Higashiyama T, Ueki M. Effects of the combined use of calcitonin and 1 alpha-hydroxycholecalciferol on vertebral bone loss and bone turnover in women with postmenopausal osteopenia and osteoporosis: a prospective study of long-term and continuous administration with low dose calcitonin. Maturitas. 2001;40(3):229-238

21. Peichl P, Rintelen B, Kumpan W, Bröll H. Increase of axial and appendicular trabecular and cortical bone density in established osteoporosis with intermittent nasal salmon calcitonin therapy. Gynecol Endocrinol. 1999;13(1):7-14.

22. Chesnut $\mathrm{CH}$ 3rd, Silverman S, Andriano K, et al. A randomized trial of nasal spray salmon calcitonin in postmenopausal women with established osteoporosis: the prevent recurrence of osteoporotic fractures study. PROOF Study Group. Am J Med. 2000;109(4):267-276.

23. Byrjalsen I, Leeming DJ, Qvist P, Christiansen C, Karsdal MA. Bone turnover and bone collagen maturation in osteoporosis: effects of antiresorptive therapies. Osteoporos Int. 2008;19(3):339-348.

24. Karsdal MA, Byrjalsen I, Leeming DJ, Delmas PD, Christiansen C. The effects of oral calcitonin on bone collagen maturation: implications for bone turnover and quality. Osteoporos Int. 2008;19(9):1355-1361.

25. MacLean C, Newberry S, Maglione M, et al. Systematic review: comparative effectiveness of treatments to prevent fractures in men and women with low bone density or osteoporosis. Ann Intern Med. 2008;148(3):197-213.

26. Cranney A, Tugwell P, Zytaruk N, et al. Meta-analyses of therapies for postmenopausal osteoporosis. VI. Meta-analysis of calcitonin for the treatment of postmenopausal osteoporosis. Endocr Rev. 2002;23(4):540-551.

27. Overgaard K, Hansen MA, Dirksen KL, Christiansen C. Rectal salmon calcitonin for the treatment of postmenopausal osteoporosis. Calcif Tissue Int. 1992;51(3):184-188.

28. Leone-Bay A, McInnes C, Wang N, et al. Microsphere formation in a series of derivatized alpha-amino acids: properties, molecular modeling, and oral delivery of salmon calcitonin. J Med Chem. 1995;38(21):4257-4262.

29. Malkov D, Angelo R, Wang HZ, Flanders E, Tang H, Gomez-Orellana I. Oral delivery of insulin with the eligen technology: mechanistic studies. Curr Drug Deliv. 2005;2(2):191-197.

30. Mustata G, Dinh SM. Approaches to oral drug delivery for challenging molecules. Crit Rev Ther Drug Carrier Syst. 2006;23(2):111-135.

31. Karsdal MA, Henriksen K, Bay-Jensen AC, et al. Lessons learned from the development of oral calcitonin: the first tablet formulation of a protein in phase III clinical trials. J Clin Pharmacol. 2011;51(4):460-471.

32. Binkley N, Bolognese M, Sidorowicz-Bialynicka A, et al. A phase 3 trial of the efficacy and safety of oral recombinant calcitonin: The ORACAL trial. J Bone Miner Res. March 21, 2012. [Epub ahead of print.]

33. Chin CM, Gutierrez M, Still JG, Kosutic G. Pharmacokinetics of modified oral calcitonin product in healthy volunteers. Pharmacotherapy. 2004;24(8):994-1001.

34. Mahato RI, Narang AS, Thoma L, Miller DD. Emerging trends in oral delivery of peptide and protein drugs. Crit Rev Ther Drug Carrier Syst. 2003;20(2-3):153-214.

35. Karsdal MA, Byrjalsen I, Henriksen K, Riis BJ, Christiansen C. Investigations of inter- and intraindividual relationships between exposure to oral salmon calcitonin and a surrogate marker of pharmacodynamic efficacy. Eur J Clin Pharmacol. 2010;66(1):29-37.

36. Karsdal MA, Byrjalsen I, Riis BJ, Christiansen C. Optimizing bioavailability of oral administration of small peptides through pharmacokinetic and pharmacodynamic parameters: the effect of water and timing of meal intake on oral delivery of Salmon Calcitonin. BMC Clin Pharmacol. 2008;8:5. 
37. Qvist P, Christgau S, Pedersen BJ, Schlemmer A, Christiansen C. Circadian variation in the serum concentration of C-terminal telopeptide of type I collagen (serum CTx): effects of gender, age, menopausal status, posture, daylight, serum cortisol, and fasting. Bone. 2002;31(1):57-61.

38. Bjarnason NH, Henriksen EE, Alexandersen P, Christgau S, Henriksen DB, Christiansen $\mathrm{C}$. Mechanism of circadian variation in bone resorption. Bone. 2002;30(1):307-313.

39. Henriksen DB, Alexandersen P, Byrjalsen I, et al. Reduction of nocturnal rise in bone resorption by subcutaneous GLP-2. Bone. 2004;34(1):140-147.

40. Karsdal MA, Byrjalsen I, Riis BJ, Christiansen C. Investigation of the diurnal variation in bone resorption for optimal drug delivery and efficacy in osteoporosis with oral calcitonin. BMC Clin Pharmacol. 2008;8:12.

41. Tankó LB, Bagger YZ, Alexandersen P, et al. Safety and efficacy of a novel salmon calcitonin ( $\mathrm{SCT}$ ) technology-based oral formulation in healthy postmenopausal women: acute and 3-month effects on biomarkers of bone turnover. J Bone Miner Res. 2004;19(9):1531-1538.

42. Karsdal MA, Alexandersen P, Dam EB, et al. Oral calcitonin demonstrated symptom-modifying efficacy and decreased cartilage volume loss: results of a 2-year phase 3 trial in patients with osteoarthritis of the knee. ACR/ARPH Scientific meeting Nov 2011, Chicago. Abstract presentation number L9.

43. Russo LA, Lau E, Tang H, et al. Efficacy and safety of oral salmon calcitonin in postmenopausal osteoporosis: randomized, double-blind, placebo-controlled trial. Abstract. American Society of Bone and Mineral Research annual meeting. Toronto, Canada; 2010.

44. Maricic MJ. Oral calcitonin. Curr Osteoporos Rep. 2012;10(1):80-85.

45. Emisphere: Salmon Calcitonin for Osteoarthritis and Osteoporosis [homepage on the Internet]. Emisphere Technologies Inc. Available from: http://www.emisphere.com/salmon_calcitonin.html. Accessed May 11, 2012.

46. Ofluoglu D, Akyuz G, Unay O, Kayhan O. The effect of calcitonin on beta-endorphin levels in postmenopausal osteoporotic patients with back pain. Clin Rheumatol. 2007;26(1):44-49.

47. Lyritis GP, Trovas G. Analgesic effects of calcitonin. Bone. 2002; 30(Suppl 5):71S-74S.

48. Azria M. Possible mechanisms of the analgesic action of calcitonin. Bone. 2002;30(Suppl 5):80S-83S.

49. Knopp-Sihota JA, Newburn-Cook CV, Homik J, Cummings GG, Voaklander D. Calcitonin for treating acute and chronic pain of recent and remote osteoporotic vertebral compression fractures: a systematic review and meta-analysis. Osteoporos Int. 2012;23(1):17-38.

50. Martinez-Zapata MJ, Roqué M, Alonso-Coello P, Català E. Calcitonin for metastatic bone pain. Cochrane Database Syst Rev. 2006;3:CD003223.

51. Altman RD, Collins-Yudiskas B. Synthetic human calcitonin in refractory Paget's disease of bone. Arch Intern Med. 1987;147(7): 1305-1308.

52. Miralles FS, Lopez-Soriano F, Puig MM, Perez D, Lopez-Rodriguez F. Postoperative analgesia induced by subarachnoid lidocaine plus calcitonin. Anesth Analg. 1987;66(7):615-618.

53. Zieleniewski W. Calcitonin nasal spray for painful diabetic neuropathy Lancet. 1990;336(8712):449.
54. Jaeger H, Maier C. Calcitonin in phantom limb pain: a double-blind study. Pain. 1992;48(1):21-27.

55. Waldburger M, Meier JL, Gobelet C. The frozen shoulder: diagnosis and treatment. Prospective study of 50 cases of adhesive capsulitis. Clin Rheumatol. 1992;11(3):364-368.

56. Gobelet C, Waldburger M, Meier JL. The effect of adding calcitonin to physical treatment on reflex sympathetic dystrophy. Pain. 1992;48(2):171-175.

57. Karsdal MA, Leeming DJ, Dam EB, et al. Should subchondral bone turnover be targeted when treating osteoarthritis? Osteoarthritis Cartilage. 2008;16(6):638-646.

58. Kwan Tat S, Lajeunesse D, Pelletier JP, Martel-Pelletier J. Targeting subchondral bone for treating osteoarthritis: what is the evidence? Best Pract Res Clin Rheumatol. 2010;24(1):51-70.

59. Hayami T, Pickarski M, Wesolowski GA, et al. The role of subchondral bone remodeling in osteoarthritis: reduction of cartilage degeneration and prevention of osteophyte formation by alendronate in the rat anterior cruciate ligament transection model. Arthritis Rheum. 2004;50(4):1193-1206.

60. Sondergaard BC, Wulf $\mathrm{H}$, Henriksen $\mathrm{K}$, et al. Calcitonin directly attenuates collagen type II degradation by inhibition of matrix metalloproteinase expression and activity in articular chondrocytes. Osteoarthritis Cartilage. 2006;14(8):759-768.

61. Sondergaard BC, Oestergaard S, Christiansen C, Tankó LB, Karsdal MA. The effect of oral calcitonin on cartilage turnover and surface erosion in an ovariectomized rat model. Arthritis Rheum. 2007;56(8):2674-2678.

62. Sondergaard BC, Madsen SH, Segovia-Silvestre T, et al. Investigation of the direct effects of salmon calcitonin on human osteoarthritic chondrocytes. BMC Musculoskelet Disord. 2010;11:62.

63. Karsdal MA, Tanko LB, Riis BJ, et al. Calcitonin is involved in cartilage homeostasis: is calcitonin a treatment for OA? Osteoarthritis Cartilage. 2006;14(7):617-624.

64. Karsdal MA, Sondergaard BC, Arnold M, Christiansen C. Calcitonin affects both bone and cartilage: a dual action treatment for osteoarthritis? Ann N Y Acad Sci. 2007;1117:181-195.

65. Karsdal MA, Byrjalsen I, Henriksen K, et al. The effect of oral salmon calcitonin delivered with 5-CNAC on bone and cartilage degradation in osteoarthritic patients: a 14-day randomized study. Osteoarthritis Cartilage. 2010;18(2):150-159.

66. Bagger YZ, Tankó LB, Alexandersen P, et al. Oral salmon calcitonin induced suppression of urinary collagen type II degradation in postmenopausal women: a new potential treatment of osteoarthritis. Bone. 2005;37(3):425-430.

67. Manicourt DH, Azria M, Mindeholm L, Thonar EJ, Devogelaer JP. Oral salmon calcitonin reduces Lequesne's algofunctional index scores and decreases urinary and serum levels of biomarkers of joint metabolism in knee osteoarthritis. Arthritis Rheum. 2006;54(10):3205-3211.

68. Manicourt DH, Azria M, Mindeholm L, Devogelaer JP. Efficacy of calcitonin therapy in patients with knee osteoarthritis: a clinical and biochemical preliminary study. Osteoarthritis Cartilage. 2005;13:s88

69. Mancini L, Paul-Clark MJ, Rosignoli G, et al. Calcitonin and prednisolone display antagonistic actions on bone and have synergistic effects in experimental arthritis. Am J Pathol. 2007;170(3):1018-1027.
International Journal of Women's Health

\section{Publish your work in this journal}

The International Journal of Women's Health is an international, peerreviewed open-access journal publishing original research, reports, reviews and commentaries on all aspects of women's healthcare including gynecology, obstetrics, and breast cancer. Subject areas include Chronic conditions (migraine headaches, arthritis, osteoporosis);

\section{Dovepress}

Endocrine and autoimmune syndromes; Sexual and reproductive health; Psychological and psychosocial conditions. The manuscript management system is completely online and includes a very quick and fair peer-review system. Visit http://www.dovepress.com/ testimonials.php to read real quotes from published authors. 